\title{
La fecha de nacimiento de Xavier Villaurrutia
}

\begin{abstract}
I A confusión sobre la fecha de nacimiento de Xavier Villaurrutia, $\mathcal{L}$ poeta y dramaturgo mexicano del presente siglo, pide una aclaración definitiva. Se cita comúnmente el año 1903, por lo general sin día o mes, ${ }^{1}$ pero existen importantes variantes: 1904 (mayo) $;{ }^{2} 1905$ (3 de diciembre) $;^{3}$ I906 (27 de marzo) . ${ }^{4}$ Es posible afirmar ahora, por medio del acta de nacimiento encontrada recientemente en el Registro Civil de México (Año 1903, Vol. 385, p. xi3) y también entre los papeles personales del poeta, que la fecha correcta es la más temprana de todas las citadas, o sea la del 27 de marzo de r903. El texto del acta sigue:
\end{abstract}

Al margen: 344 Trescientos cuarenta y cuatro. Villaurrutia y GonZÁlezZ, JAvier. Al centro: En la ciudad de México, a las II once y ro minutos de la mañana del día ir once de abril de 1903 mil novecientos tres, ante mí, Leopoldo Ortega, Oficial $3^{9}$ tercero del Estado Civil, compareció el ciudadano Rafael Villaurrutia de México, casado, de 40 cuarenta años, comisionista, vive en la

I En la mayoría de los manuales y antologías en que figura Villaurrutia se cita simplemente el año 1903; Ocbo Poetas (México, 1903), p. 123, cita el 3 de diciembre de 1903; Raúl Leiva, Imagen de la poesía mexicana contemporánea (México, 1959), p. 151, da la fecha correcta, el 27 de marzo de 1903.

2 Ugo Gallo, Storia della Letteratura Ispano-Americana (Milano, 1954), da el año de 1904; en una noticia sobre la muerte de Villaurrutia publicada en Novedades, 26 de diciembre de 1950, p. 1, Helia D'Acosta cita marzo de 1904; Frank Dauster, "The Literary Art of Xavier Villaurrutia" (tesis inédita, Univ. de Yale, 1953), p. 16, cita el 3 de diciembre de 1904.

3 Who's Who in Latin America, ed. Ronald Hilton. Part I: México (Stanford Univesrity Press, 1946).

4 En noticias sobre la muerte de Villaurrutia, El Universal, 26 de diciembre de 1950, p. 6, y La Prensa, 26 de diciembre de 1950, p. 2, citan marzo de 1906; Anthony W. Moreno, "Xavier Villaurrutia: The Man and His Dramas" (tesis inédita. Univ. de Pittsburgh, 1953), p. 3, de el 27 de marzo de 1906. 
3a. tercera de Mina número 5 cinco y presentó vivo al niño Javier, que nació en dicha casa el día 27 veintisiete del mes próximo pasado a las ix once de la mañana, hijo legítimo suyo y de su esposa la señora Julia González de Chihuahua, de 32 treinta y dos años, vive con su esposo. El niño presentado es nieto por línea paterna de los finados ciudadanos Agustín Villaurrutia y señora Petra Trigueros y por la materna del también finado ciudadano Celso González y de su viuda la señora Josefa Casabantes de Chihuahua donde reside. Fueron testigos los ciudadanos Javier Villaurrutia y Baldomero Velázquez, mayores de edad de México, casados, empleados, el primero vive en la 5 a. quinta de Mina número I y $3 / 4$ uno $y$ tres cuartos el segundo en la $4^{\mathrm{a}}$ cuarta de Mina número $\mathrm{I}$ uno. Leída esta acta la ratificaron y firmaron.-L. Ortega.-Rafael Villaurrutia.-Javier Villaurrutia.-B. Velázquez.-Rúbricas.

Es interesante especular sobre la confusión de un dato tan accesible. En primer lugar, se explica fácilmente la frecuente cita del día 3 de diciembre. En buena forma hispánica, Villaurrutia observaba, no su propio día de nacimiento sino el día de su santo, que en este caso caía en el 3 de diciembre.5 También es posible que después de la muerte de Villaurrutia la familia haya contribuido a la confusión; Anthony Moreno, por ejemplo, propone una fecha bastante alejada de la verdadera, a base de una entrevista que él sostuvo con la familia. 6 Por último, parece indudable que Villaurrutia mismo multiplicó conscientemente la confusión de fechas. Hay varios documentos entre sus papeles personales (tarjetas de identidad, listas de datos biográficos en su propia letra, etc.) en que figuran fechas erróneas, particularmente las de x904 y r905. Estos documentos, con otros que acentúan la obsesión con una vejez prematura (por ejemplo una fotografía sacada a los 26 años que lleva la anotación: "Envejezco?"), sugieren fuertemente que Villaurrutia acostumbraba "quitarse años" cuando se le presentaba la oportunidad.

\section{MERLIN H. Forster}

\section{University of Illinois}

5 El 3 de diciembre es el día de San Francisco Xavier, que murió en esta fecha en el año de 1552. Según el Cátbolic Almanac (Garden City, N. Y., 1966), los días festejados en honor de los santos caen muchas veces en el día de su muerte, "which marked the beginning or birthday (dies natalis) of their everlasting happiness in heaven" (p. 141).

6 Moreno dice: "A personal interview with surviving members of his family confirms the latest [i.e. 1906] of the three years" (p. 3, n. 2). 